\title{
ALGUMAS IMPRESSÕES ACERCA DA MÍMESIS E DO SUJEITO FRATURADO
} SOME IMPRESSIONS ABOUT THE MESSAGE AND THE FRACTURED SUBJECT

Vera R. V. Dupont ${ }^{l}$

\begin{abstract}
RESUMO: Este trabalho tem por objetivo realizar a verificação do novo conceito de mímesis e de sujeito fraturado, propostos por Luiz Costa Lima (2000), fazendo uma reflexão por meio da leitura da obra Notas de Subsolo, do escritor russo Dostoievski, bem como do conto "Felicidade", de Luis Vilela. Deste modo, pretende-se realizar uma análise bibliográfica para verificar como esses novos conceitos perpassam a complexidade humana, expressa na figura do narrador, o Homem do Subsolo, que demostra perturbação e pessimismo acerca das relações humanas, bem como um profundo pesar que expressa sobre seu próprio fracasso existencial. Para a consecução desta análise, tomar-se-á como embasamento teórico autores como Schopenhauer (2013) e Foucault (2008), dentre outros.
\end{abstract}

Palavras-chave: Mímesis; sujeito-fraturado; Literatura

\begin{abstract}
The objective of this work is to verify the new concept of mimesis and fractured subject, proposed by Luiz Costa Lima (2000), by means of the reading of the work Notes of Underground by the Russian writer Dostoyevsky, as well as tale "Happiness", by Luis Vilela. In this way, it is intended to carry out a bibliographical analysis to verify how these new concepts pervade the human complexity, expressed in the figure of the narrator, the Man of the Subsoil, which shows disturbance and pessimism about human relations, as well as a deep sorrow expressed on his own existential failure. To achieve this analysis, authors such as Schopenhauer (2013) and Foucault (2008), among others, will be taken as theoretical basis.
\end{abstract}

Keywords: Mimesis; subject-fractured; Literature.

\section{A LITERATURA E O SUJEITO FRATURADO: A MÍMESIS POR LUIZ COSTA LIMA}

Uma obra de arte, quer seja uma música, uma escultura, uma pintura ou obra literária, é capaz de provocar inúmeras sensações e produzir efeitos diversos por parte do receptor. É possível perceber que a arte nunca é algo fechado, uma vez que apresenta inúmeras possibilidades, dependendo do contexto daquele que irá completá-la com suas percepções e sensações.

É sobre a arte das palavras que esta análise se debruça: a Literatura. Esta, como expressão da arte por meio das palavras, acompanha o homem e nos dá a percepção de como esse homem compreende o mundo, qual é a escala de valores que está permeando a obra em personagens representadas ou não, por meio de seus discursos ou de seus "não-ditos". Afinal, de acordo com Eni Orlandi (1995, p. 55), "Dizer ou calar não é vazio de sentido, até o silêncio tem um sentido."

\footnotetext{
${ }^{1}$ Doutoranda, UNIOESTE, veravargas@bol.com.br
} 
Para realizar esta análise bibliográfica, é importante rever os conceitos de Antonio Candido acerca de como a obra, no caso a literária, está imbricada com o contexto social. Em sua obra Literatura e Sociedade (2000, p.17), Cândido chama atenção para os “aspectos sociais que envolvem a vida artística e literária nos seus diferentes momentos" e submete à minuciosa análise a influência que o meio social exerce sobre a obra de arte e a influência desta sobre o meio. Afirma que há uma tendência da estética moderna em estudar "como a obra de arte plasma o meio" (CANDIDO, 2000, p.18). Destaca, ainda, as influências concretas dos fatores socioculturais no que aponta como quatro momentos da produção artística: "[...] É difícil discriminá-los, na sua quantidade e variedade, mas pode-se dizer que os mais decisivos se ligam à estrutura social, aos valores e ideologias, às técnicas de comunicação.” (CANDIDO, 2000, p. 21). Isto se dá da seguinte maneira: “[...] a) o artista, sobo impulso de uma necessidade interior, é orientado segundo padrões da sua época, b) escolhe certos temas, c) usa certas formas e d) a síntese resultante age sobre o meio." (CANDIDO, 2000, p. 21).

Candido (2000, p.14) enfatiza que “[...] o fator social é invocado para explicar a estrutura da obra e o seu teor de ideias, fornecendo elementos para determinar a sua validade e o seu efeito sobre nós”, de modo que “[...] não convém separar a repercussão da obra da sua feitura, pois, sociologicamente ao menos, ela só está acabada no momento em que repercute e atua, porque, sociologicamente, a arte é um sistema simbólico de comunicação inter-humana [...]". (CANDIDO, 2000, p.21). Assim, segundo Antonio Candido, só podemos interpretar dialeticamente uma obra em sua integridade se fundirmos o texto e o contexto, ou seja, os elementos estéticos da obra com os elementos sociais. O pesquisador salienta que é devido à necessidade de representações de mundo que surge a criação literária e, portanto, mesmo sem intencionalidade, o artista revela seu contexto social pelas representações que faz. "[...] O público dá sentido e realidade à obra, e sem ele o autor não se realiza, pois ele é de certo modo o espelho que reflete a sua imagem enquanto criador" (CANDIDO, 2000, p.38). Desta feita, autor-obra-público formam uma tríade inseparável na compreensão de uma obra de arte, especialmente da obra literária, pois é importante analisar como o texto literário descortina a realidade.

O que se constata, a partir dessas assertivas, é que não há como isolar a literatura da sociedade, pois, ambas exercem influência uma sobre a outra, seja através da retomada do contexto por meio do texto, seja através da criação ou intensificação de novas formas de agir e pensar a partir do discurso produzido pela literatura. Assim sendo, é importante analisar como o texto literário descortina a realidade. Isto norteará esta análise para verificar como se dão as relações sociais e individuais da personagem na busca pelo bem-estar.

Aristóteles, em sua obra Poética (2017), apresenta o conceito de mímesis, para a arte poética, em sua acepção mais geral, sendo a imitação. Para Platão, esse conceito é pejorativo, já que não 
permite ao cidadão uma aproximação do "mundo real". Já Luiz Costa Lima (2000), em sua obra Mímesis: Desafio ao Pensamento, faz uma nova leitura desse conceito: a dissociação entre mímesis e imitativo.

Deste modo, o conceito de homem fragmentado é essencial para que descortinemos os invólucros, em uma desconstrução do modo tradicional e clássico de perceber a questão da mímesis, tida classicamente como simples imitação, representação que confirma a realidade da natureza.

Por sujeito fraturado ou fragmentado entende-se o conceito que vai contra a percepção de unidade e pureza da crítica canônica da mímesis clássica. Luiz Costa Lima (2000) apresenta a necessidade de compreender uma nova mímesis, não mais pautada em reproduções de algo já visto, ou de um modelo dado, mas, que provoque deslocamentos do sujeito. O sujeito dessa mímesis é um sujeito cuja perspectiva é a do fragmento, da compreensão de que não existe uma unidade. Esse sujeito, repleto de heterogeneidade e contradições, é também cheio de fissuras pelas quais o olhar do outro consegue penetrar.

Conforme Luiz Costa Lima (2000), o conceito de mímesis tem um caráter de um processo complexo criativo, pautado em resultados de uma produção de diferenças, não apenas de imitação de determinada realidade. O espaço ficcional literário é, assim, um local que desestabiliza e também permite o alcance da estabilidade que o eu procura.

Há, portanto, com a concepção mimética da fratura, desconstruções dos discursos clássicos da perspectiva do uno: a tessitura dos discursos, na contemporaneidade, é feita de forma a desvendar omissões, apagamentos e silenciamentos, de modo a construir uma história de recortes, de desmoronamento do sagrado e das verdades absolutas. É o sujeito plural, deslocado, que questiona a tentativa de unificação e despedaça as certezas. Assim, as dualidades, o binarismo cartesiano e o positivismo excludente, dão lugar a uma nova interpretação que, conforme Silviano Santiago, fica no entre lugar, no devir, em um lugar em construção.

Observa-se, portanto, que esse novo modo de compreensão do mundo, que foge da mímesis como a transfiguração do real de Aristóteles e do imitativo de Platão, em vez de reificar o discurso de poder, quer desconstruir esse discurso de modo a ressignificá-lo. Há uma espécie de desleitura, já que o sujeito fraturado surge da crise do sistema cartesiano, em uma necessidade de repensar as estruturas mentais do homem de interpretar o mundo.

Desta forma, configura-se uma crise da representação, em que não há mais a possibilidade da existência do homem uno e inteiro, já que há o questionamento do racionalismo. O herói inteiro e sem dúvida cai por terra e surge o ser que duvida. Isto reifica a crise das narrativas fundadoras da identidade e da identidade. O mundo, assim, é visto como mais complexo do que os dogmas criados institucionalmente. 
Michel Foucault, em A arqueologia do saber, ao tratar das unidades do discurso, aponta a descontinuidade do mesmo: "O emprego dos conceitos de descontinuidade, de ruptura, de limiar, de limite, de série, de transformação, coloca, a qualquer análise histórica, não somente questões de procedimento, mas também problemas teóricos." (FOUCAULT, 2008, p. 23).

Um exemplo de obra dessa nova mímesis é a obra Notas de Subsolo, de Dostoievski, que leva o leitor a aproximar-se de um narrador, o homem do subsolo, cujo pessimismo e complexidade já está presente no início da narrativa: "Sou um homem doente... Sou mau. Não tenho atrativos. Acho que sofro do fígado." (Dostoievski, 2008, p. 7). Um sujeito nada convencional, que provoca deslocamentos em uma arte humanizadora e transgressora, que provoca uma desconstrução do olhar e não uma naturalização do sentir, em uma contradição do sujeito que afirma e logo adiante nega o que disse. A nova mímesis tem um fundo de semelhança mas tem um retorno na diferença.

O narrador de Dostoievski, em Notas de Subsolo, faz o discurso da diferença, em um fluxo de consciência que aponta a dúvida, o entre-lugar, a confirmação da dúvida daquele que não se enquadra nos binarismos cartesianos:

\begin{abstract}
Como se tal muro de pedra fosse de fato um alívio e contivesse uma palavra que fosse para o mundo, unicamente por ele ser dois mais dois são quatro. Ó, cúmulo do absurdo! Muito melhor é compreender tudo, perceber tudo, todas as impossibilidades e muros de pedra; não se resignar diante de nenhuma dessas impossibilidades e muros de pedra, se isso lhe repugna; através das mais inevitáveis combinações lógicas, chegar às conclusões mais abomináveis sobre o eterno tema de que até desse muro de pedra você de certa forma é o próprio culpado, embora esteja perfeitamente claro e evidente que você não é culpado, e, em consequiência disso, rangendo os dentes impotente e calado, ficar paralisado numa inércia voluptuosa, vendo em seus devaneios que na realidade você nem tem alguém de quem possa ter raiva; que não se encontra o objeto e que talvez nunca seja encontrado, que aqui existe uma fraude, um embuste, uma trapaça, existe simplesmente algo intragável - não se sabe o que, não se sabe quem, mas que, apesar de todas essas incógnitas e embustes, é doloroso para você, e quanto mais desconhecido, mais doloroso é! (Dostoievski, 2008, p. 13).
\end{abstract}

O mesmo pensamento do homem do subsolo se apresenta na obra de Mario Vargas Llosa (2002) que, ao analisar a obra La muerte em Venecia, de Thomas Mann, faz a reflexão de que a ordem permite a vida social ao mesmo tempo em que não basta para garantir a felicidade individual:

La razón, el orden, la virtud, aseguran el progreso del conglomerado humano pero rara vez bastan para hacer la felicidad de los individuos, en quienes los instintos reprimidos en nombre del bien social están siempre al acecho, esperando la oportunidad de manifestarse para exigir de la vida aquella intensidad y aquellos excesos que, en última instancia, conducen a la destrucción y a la muerte. (VARGAS LLOSA, 2002, p. 11).

Assim, a personagem Gustav von Aschenbach, de Tomas Mann, que após uma vida regrada e voltada à sisudez passa a experimentar, através de seus pensamentos, os prazeres da vida ao manter uma paixão platônica por um belo jovem que conhece em Veneza, se vê dominada por seus desejos 
íntimos e revela que o desejo humano está pautado em uma tensão que de longe se aproxima do sujeito uno.

O conto "Felicidade", do escritor mineiro Luis Vilela, também apresenta a história de um sujeito fragmentado: o tema abordado é a questão das aparências, do enquadramento social a que as pessoas são submetidas por fazerem parte de um grupo. O tema é a perspectiva de felicidade, que nem sempre e dificilmente é igual a todas as pessoas ou sociedades. Então, vemos no fluxo psicológico da personagem, o desejo de fugir do pensamento cartesiano, sendo um conto que provoca no leitor a possibilidade de questionar e desconstruir o discurso de felicidade e vida ideal.

Vemos, deste modo, a fragilidade da personagem Edgar diante das regras de ajustamento social, buscando manter uma aparência mesmo em um estado dissonante: ele abre mão de seu verdadeiro desejo em prol do convívio harmônico com o grupo de convidados de sua esposa. Ela, que organizou a tal festa, vale-se de sua própria concepção de felicidade, acreditando que seu marido também comungaria de tal visão. A personagem, apesar de não desejar tal situação e estar em meio a um conflito interno amedrontador, vê-se em meio às cobranças implícitas da mulher, confessadas pela troca de olhares, tentando convencê-lo de que ele precisa discursar por ser o papel social que lhe cabe naquele momento.

Observa-se que o comportamento da personagem desse conto permite que avaliemos o comportamento humano diante do mundo real, sobremaneira acerca do homem contemporâneo e os papeis sociais que precisa desempenhar. Se por um lado há a busca pela obediência aos parâmetros delimitadores da convivência social, para que haja uma satisfação, há, por outro, uma grande insatisfação por não poder realizar os desejos pessoais mais íntimos, em um paradoxo da complexidade humana.

Verifica-se que Freud faz a oposição entre Eros, que é o instinto de vida e o seu principal adversário, e Tânatos, a pulsão de morte. Para ele, a história da civilização é uma luta contínua e sem resolução entre esses dois impulsos, que precisam ser mantidos em equilíbrio pelos indivíduos:

A sublimação do instinto constitui um aspecto particularmente evidente do desenvolvimento cultural; é ela que torna possível às atividades psíquicas superiores, científicas, artísticas ou ideológicas, o desempenho de um papel tão importante na vida civilizada. Se nos rendêssemos a uma primeira impressão, diríamos que a sublimação constitui uma vicissitude que foi imposta aos instintos de forma total pela civilização. (FREUD, 1927, p. 63).

Percebe-se, deste modo, que, conforme Freud, o processo civilizatório envolve sufocar muitos dos impulsos sexuais e de agressão que estão ligados ao prazer. A própria cultura provocaria, conforme esse autor, um mal-estar na dicotomia entre o prazer individual e as exigências da civilização. Isto é evidente na conduta da personagem de Luiz Vilela, que se sente esmagado entre as 
obrigações sociais e o desejo de realização pessoal: ficar sozinho lhe proporcionaria um bem-estar profundo, mas que o faria romper com a espécie de pacto social que mantinha estabelecido com amigos e familiares.

Em "Felicidade Clandestina", da escritora Clarice Lispector, apresenta o sujeito fraturado, mostrando sua subjetividade no momento em que se aproxima do objeto de desejo tão esperado:

\footnotetext{
Chegando em casa, não comecei a ler. Fingia que não o tinha, só para depois ter o susto de o ter. Horas depois abri-o, li algumas linhas maravilhosas, fechei-o de novo, fui passear pela casa, adiei ainda mais indo comer pão com manteiga, fingi que não sabia onde guardara o livro, achava-o, abria-o por alguns instantes. Criava as mais falsas dificuldades para aquela coisa clandestina que era a felicidade. A felicidade sempre iria ser clandestina para mim. (LISPECTOR, 1998, p. 10).
}

A narradora parece temer a felicidade, em um discurso que coloca em prova o próprio conceito de felicidade em prova, demonstrando que não existem verdades absolutas ou que existem muitas verdades.

Em A Arte de conhecer a si mesmo, Schopenhauer (2013, p. 3) afirma que o querer, a vontade, é o que de pior há em nós: “Querer o menos possível e conhecer o mais possível, eis a máxima que conduziu minha trajetória de vida. Pois a vontade é o que há de mais comum e de pior em nós."

O personagem de Dostoievski, em Notas de Subsolo, é um anti-herói, marcado de excentricidade: é um sujeito dissonante, que se vê irregular em meio ao contexto "regular" da modernidade, representando uma consciência incoerente e contraditória. O homem do subsolo, deste modo, demonstra a condição individualizada do homem moderno, que sofre diante da indiferença da civilização iluminista. Vê-se, portanto, em uma espécie de sufocamento, uma vez que evidencia uma semelhança com a personagem da obra Metamorfose, de Kafka: "[...] Agora desejo lhes contar, queiram ou não ouvir, por que não consegui me tornar nem ao menos um inseto. Afirmo-lhes solenemente que muitas vezes quis tornar-me um inseto. " [...] (DOSTOIEVSKI, 2008, p. 8).

Nota-se que há uma inclinação da personagem para valorizar a intelectualidade, sendo para ele um momento de autoafirmação, um modo de escamotear seu sofrimento diante de seu fracasso: “[...] Agora vivo no meu canto, provocando a mim mesmo com a desculpa rancorosa e inútil de que o homem inteligente não pode seriamente se tornar nada, apenas o tolo o faz." (DOSTOIEVSKI, 2008, p. 8). Fala, ainda, do homem normal, oriundo da natureza: “[...] Invejo tal homem até a minha última gota de fel. Ele é um imbecil, indiscutivelmente, mas pode ser que o homem normal deva ser mesmo imbecil, quem sabe? (DOSTOIEVSKI, 2008, p. 11).

Do mesmo modo, observa-se em Schopenhauer (2013), a percepção de que a intelectualidade está acima do que seria uma trajetória normal, de um indivíduo que tem emprego, casa, jardim, esposa e filho, já que 
[...] A existência desses indivíduos transcorre de maneira sempre igual. Já a minha vida, ao contrário, é intelectual, e seu desenvolvimento regular e atividade constante têm de produzir frutos nos poucos anos de pleno poder espiritual e de sua livre utilização, e, assim, por séculos enriquecer a humanidade. (SCHOPENHAUER, 2013, p. 3)

O questionamento de uma vida regida pelo cientificismo, tão presente nas descobertas darwinianas e pela ordem e progresso positivista, pode ser percebida em Dostoievski, que reflete sobre o processo da vida humana, na seguinte passagem:

\begin{abstract}
As veneráveis formigas começaram com um formigueiro e terminarão também, provavelmente, com um formigueiro, o que muito honra sua constância e sua natureza positiva. Mas o homem é um ser inconstante e pouco honesto e, talvez, à semelhança do jogador de xadrez, goste apenas do processo de procurar atingir um objetivo, e não do objetivo em si. E quem sabe? Não se pode garantir, mas talvez todo o objetivo a que o homem se dirige na Terra se resuma a esse processo constante de buscar conquistar ou, em outras palavras, à própria vida, e não ao objetivo exatamente, o qual, evidentemente, não deve passar de dois e dois são quatro, ou seja, uma fórmula, e dois e dois são quatro já não é vida, senhores, mas o começo da morte (DOSTOIEVSKI, 2008, p. 26).
\end{abstract}

O sujeito do subsolo, portanto, é um sujeito que questiona a nova ordem tida como verdadeira. É capaz de perceber que, diante de uma estrutura cartesiana, há pouco espaço para a subjetividade humana e sua complexidade.

Ao realizar uma análise da obra Notas de Subsolo, de Dostoievski, percebe-se que a mesma comunga de uma mesma visão de mundo da obra de Schopenhauer. Conforme Schopenhauer (2013), há um distanciamento do ser que afirma ser de natureza completa e dos seus semelhantes:

Se a vantagem do ser humano se confirma no fato de ele - mais do que qualquer animal de outra espécie - ser independente e completo, então decerto a vantagem superior de uma pessoa reside no maior grau com que ela desenvolve em si mesma essas características diante do outro. Uma pessoa, portanto, que em suas visões e ações, em sua formação e produtividade, ou em todos os pontos de contato de sua existência com os seres de sua espécie, de certa forma gravita em torno de si, e que, devido à sua natureza completa, distancia-se da esfera de seus semelhantes num grau, por assim dizer, em que apenas um pequeno ponto de contato, uma tangente entre ela e a espécie humana é formada - tal pessoa pode ser tranquilamente incluída entre as mais excelsas e magnânimas (SCHOPENHAUER, 2013, p. 92).

Deste modo, conforme Luiz Costa Lima, é possível perceber que tais obras seguem uma nova concepção mimética: é a arte literária capaz de abordar o sujeito com fraturas, em um universo de desconstruções dos discursos. Observa-se que o comportamento da personagem da história ficcional permite que avaliemos o comportamento humano diante do mundo real, sobremaneira acerca do homem contemporâneo. É possível observar, portanto, um novo conceito de sujeito se revela por meio da literatura; verifica-se que esse sujeito representado é multifacetado, capaz de se desprende do discurso previsível produzido pela história. A literatura, por ser espaço das discussões sociais que 
apoquentam o ser humano, representa esse tema e provoca reflexões acerca dele, já que quer na ficção, quer na realidade, é um tema cotidiano e atual.

\section{BIBLIOGRAFIA}

ARISTÓTELES. Poética. Edição bilíngue; tradução, introdução e notas de Paulo Pinheiro. 2 ed. São Paulo: Editora 34, 2017.

CANDIDO, Antonio. Crítica e Sociologia. In: Literatura e Sociedade. 8.ed. São Paulo: T. A. Queiroz, 2000.

DOSTOIEVISKI, Fiodór. Notas de Subsolo. Trad. Maria Aparecida B. P. Soares. Porto Alegre: L\&PM Editores, 2008. Disponível em <http://sanderlei.com.br/PDF/Fiodor-MikhailovitchDostoievsk-Fedor-Dostoievski/Fiodor-Mikhailovitch-Dostoievsk-Fedor-Dostoievski-Notas-do-

Subsolo.pdf>, acesso em 15/06/2017.

FREUD, Sigmund. O mal-estar na civilização [1929]. In: Edição Standart. Rio de Janeiro: v. XXI. Imago, 1974.

LIMA, Luiz Costa. Mímesis: Desafio ao Pensamento. Rio de Janeiro: Civilização Brasileira, 2000.

LISPECTOR, Clarice. Felicidade Clandestina - Contos. Rio de Janeiro: Rocco, 1998.

SANTIAGO. Silviano. Meditações sobre o ofício de criar. Aletria, 2008 - jul.-dez. - v. 18.

SCHOPENHAUER, Arthur. A Arte de conhecer a si mesmo. São Paulo: WMF Martins Fontes, 2013. VARGAS LLOSA, Mario. La verdade de las mentiras. Alfaguara: 2002. Disponível em <http://biblioteca.unedteruel.org/la_biblioteca_recomienda/la_verdad.pdf $>$, acesso em 13/04/2017.

VILELA, Luiz. Felicidade. In O novo conto brasileiro: antologia crítica com anotações e exercícios gramaticais / Malcolm Silvermann - Rio de Janeiro: Nova Fronteira, 1985.

FOUCAULT, Michel. As unidades do discurso. In: A arqueologia do saber. Trad. Luiz Felipe Baeta Neves. 7 ed. Rio de Janeiro: Forense, 2008.

ORLANDI, Eni Puccinelli. As formas de silêncio: no movimento dos sentidos. Campinas, SP: Ed. UNICAMP, 1995. 